\title{
Scaling of Quasi-Brittle Fracture and the Fractal Question
}

Zdeněk P. Bažant Waiter F Murony Proiessor of Civil Engineering and Materầis Sc ence. Northwesier] University. Evansica. IL 30208
The paper represents an extended text of a lecture presenting a review of recent results on scaling of failure in structures made of quasibrittle materials, characterized by a large fracture process :one, and examining the question of possible role of the fractal nature of crack surfaces in the scaling. The problem of scaling is approached through dinensional analysis, the laws of thermodynamics and asymptotic matching. Large-size and small-size asymptotic expansions of the size effect on the nominal strength of structures are given. for specimens with large notches (or traction-free cracks) as well as zero notches. and simple size effect formulas matching the required asymptotic properties are reported. The asymptotic analysis is carried out. in general. for fractal cracks, and the practically important case of nonfractal crack propagation is acquired as a special case. Regarding the fractal nature of crack surfaces in quasibrittle materials, the conclusion is that it cannot play a signification role in fracture propagation and the observed size effect. The reason why Weibull statisticai theory of random material strength does not explain the size effect in quasibrinlc failures is explained. Finally, some recent applications to fracture simulation iy particle models (discrete element method) and to the determination of size effect and fracture characteristics of carbon-epory composite laminates are oriefly revieved.

\section{Introduction}

Scaling is the essertiai characteristic of every physical theory. However. in mecinanics of materials. little attention has been paid to the scaling of tailure. More than a dozen years ago. the observed effect of structure size on the nominal strength of a structure had generally been explained by Weibull-type theories of random strength. However. careful recent analysis (Bažant and $\mathrm{Xi} .1991$ ) indicates that this Weibull-type theory does not capture the essential cause of size effect for quasibrittle materials such as rocks, toughened ceramics, concretes, mortars, brittle fiber composites. ice (especially sea ice), wood particle board and paper. in which the fracture process zone is not small compared to structural dimensions and large stable crack growth occurs prior to failure. Rather. the dominant source of size effect in these materials is deterministic and consists in the global release of stored energy from the structure as a result of large fracture and the associated redistribution of stresses.

Approximate analysis of the global energy release was shown to lead to a simple size effect law (Bażant 1983. 1984) for quasi-brittle fracture. This law subsequently received extensive justifications, based on: (1) comparisons with tests of notched fracture specimens of concretes. mortars, rocks, ceramics, fiber composites (Bažant and Pfeiffer, 1987: Bažant and Kazemi. 1990a,b; Bažant et al., 1991; Gettu et al.. 1991. Bažant et al.. 1994: Bažant et al., 1995) as well as unnotched reinforced concrete structures, (2) similitude in energy release and dimensional analysis, (3) comparison with discrete element (random particle) numerical model for tracture (Bažant et al., 1990: Jirásek and Bažant. 1995). (t) derivation as a deterministic limit of a nonlocal generalization of Weibull statistical theory of strength (Bažant and $\mathrm{Xi} .1991$ ), and (5) comparison with finite element solutions based on nonlocal model of damage (Bažant et al., 1994). The simple size effect law has been shown useful for evaluation of material fracture characteristics from tests. Significant contributions to the study of size effects in quasi-brittle fracture have also been made by Carpinteri (1986). Planas and Elices (1988a.b), van Mier (1986) etc.

\footnotetext{
Contributed by the Materials Division for Publication in the Jol Rval of EvGi. NEERNG MATERIaLs and TECHNOLOGY. Manuscript received by the Materials Division July 10, 1995. Associate Technical Editor: G. J. Weng.
}

Recently, the fractal nature of srack surfaces in quasioritite materiais (Mandelbrot et al. 1984: Mecholsky and Mackin. 1988: Molosov and Borodich, 1992: Borodich. 1992: Xie. 1993. etc.) has been studied and it has been suggested that the crack surface fractality might be an altemate source of the observed size effect (Cappinteri, 1994; Carpinteri et al., 1993, 1995; Lange et al., 1993, and Saouma et al.. 1990, 1994).

This paper, which represents the expanded text of a lecture at the Diamond Jubilee Symposium of ASME Materials Division held in San Francisco in November, 1995. presents a generalized asymptotic theory of scaling of quasibritule fracture and also explores the possible roie of the crack surface fractality in the size effect. Some selected applications to particulate materiai modeis and to fracture testing of tiore composite laminates are also briefly demonstrated.

\section{Large-Size Asymptotic Expansion of Size Effect for Nonfractal and Fractal Fracture}

For the sake of generality we will conduct the analysis for fractal cracks and the noniractal case will then simply ensue as $a$ limit case. Let us consider a crack representing a fractal curve (Fig, 1) whose length is defined as $a_{b}=\delta_{0}\left(a / \delta_{0}\right)^{d}$ : where $d$, $=$ fractal dimension of the crack curve $(\geq 1)$ and $\delta_{3}=$ lower limit of fractality implied by material microstructure, which may be regarded as the length of a ruler by which the srack length is measured (Mandelbrot et al.. 1984). Unlike the case of classical, nontractal fracture mechanics, the energy dissipated per unit length of a fractal crack cannot be considered as a material constant because the length of a fractal curve is intinite. Rather. the energy $\pi$, dissipated by a fractal crack in a twodimensional body of thickness $b$ needs to be defined as

$$
\tau_{f} / b=G_{f l} a^{d_{f}}
$$

where $G_{f l}=$ fractal fracture energy, of dimension $J m^{-d_{f}-1}$. A nontractal crack is the special case for $d_{f}=1$, and in that case $G_{1 /}$ reduces to $G_{f}$, representing the standard fracture energy, of dimension $\mathrm{Jm}^{-2}$. Fractality of the crack surface profiles across thickness $b$ is not considered.

The following three hypotheses will be introduced: 


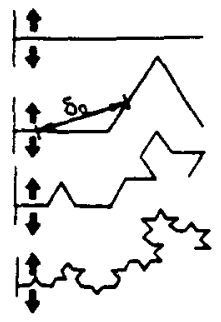

Fig. 1 Von Koch curves as examples of tractal crack at progreseive refinement

1. Within a cerain range of sufficiently small scales, the failure is caused by propagation of a single fractal crack.

2. The fractal fracture energy, $G_{f \prime}$ is a material constant correctly defining energy dissipation.

3. The material may (although need not) possess a material length, $c_{f}$.

The rate of macroscopic energy dissipation $\xi_{c r}$ with respect to the "smooth" (projected. Euclidean) crack length $a$ is:

$$
\xi_{c r}=\frac{1}{b} \frac{\partial \mathbb{G}_{f}}{\partial a}=G_{f l} d_{f} a^{d,-1}
$$

(e.g., Borodich, 1992; Molosov and Borodich, 1992). To characterize the size effect in geometrically similar structures of different sizes $D$ (characteristic dimensions), we introduce, as usual. the nominal stress $\sigma_{N}=P / b D$ where $D=$ characteristic size (dimension) of the structure, $P=$ dead load applied on the structure (or load parameter), and $b=$ structure thickness in the third dimension (we restrict attention to two-dimensional similarity; generalization to three-dimensional similarity is obvious). When $P=P_{\max }=$ maximum load, $\sigma_{N}=$ nominal strength.

The material length, $c_{f}$, may be regarded as the size (smooth. or projected) of the fractal fracture process zone in an infinitely large specimen (in which the structure geometry effects on the process zone disappear). The special case $c_{f}=0$ represents fractal generalization of linear elastic fracture mechanics (LEFM). Alternatively, if we imagine the fracture process zone to be described by smeared cracking or continuum damage mechanics, we may define $\left.c_{f}=\left(G_{f l} / W_{d}\right)^{1 /(z-d,}\right)$ in which $W_{d}$ $=$ energy dissipated per unit volume of the continuum representing in a smeared way the fracture process zone (area under the complete stress-strain curve with strain softening). As still another alternative. in view of nonlinear fracture mechanics such as the cohesive crack model, we may define $c_{f}=$ $\left(E G_{f 1} / f_{t}^{2}\right)^{1 /\left(2-d_{f}\right)}$ in which $E=$ Young's modulus and $f_{t}=$ material tensile strength.

There are two basic variables, $a$ and $c_{f}$, both having the dimension of Euclidean length. We will introduce two dimensionless variables: $\alpha=\alpha / D$ and $\theta=c_{f} / D$. According to Buckingham's theorem of dimensional analysis (c.g., Sedov, 1959; Barenblath, 1979), the complementary energy $\Pi^{*}$ of the structure with a fractal crack may be expressed in the form:

$$
\Pi^{*}=\frac{\sigma_{N}^{2}}{E} b D^{2} f(\alpha, \theta)
$$

in which $f$ is a dimensionless continuous function of $\alpha$ and $\theta$, characterizing the geometry of the structure and loading.

The laws of thermodynamics must be satisfied by nonfractal as well as fractal cracks. Let us begin with the first law, i.e., energy balance. In this respect, note that the energy release from the structure as a whole must be calculated on the basis of $a$ rather than $a_{8}$. Indeed, the smooth length $a$ is the length that matters for the overall strain energy of the elastic stress field on the macroscale. Therefore, $\partial \Pi * / \partial a=\partial \eta_{f} / \partial a$. Substituting (2) and differentiating. we obtain

$$
\frac{\sigma_{*}^{2}}{E} D g(\alpha, \theta)+2 D^{2} f(\alpha, \theta) \frac{\sigma_{v}}{E} \frac{\partial \sigma_{v}}{\partial a}={ }^{\prime},
$$

in which $g(\alpha, \theta)=\partial f(\alpha, \theta) / \partial \alpha=$ dimensionless energy release rate.

According to the second law of thermodynamics, the condition of stability of equilibrium state of a structure is equivalent (e.g., Bażant and Cedolin, 1991, chapter 10) to the condition $\partial P / \partial a>0$. At the stability limit, $\partial P / \partial a=0$ which coincides with the condition of maximum load. Therefore. if we are interested in the size effect on the load at the limit of stability, that is, the maximum load or nominal strength. we have the condition $\partial \sigma_{N} / \partial a=0$. So, Eq. (4) gives:

$$
\sigma_{N}=\sqrt{\frac{E_{\mathrm{G}}^{\mathrm{G}_{\mathrm{sg}}}}{D_{\mathrm{g}}\left(\alpha_{0}, \theta\right)}}
$$

where $\alpha_{0}=$ relative crack length $\alpha$ at maximum load.

\section{Fractal and Nonfractal Scaling Laws}

Because function $g\left(\alpha_{0}, \theta\right)$ ought to be smooth, we may expand it into Taylor series about the point $(\alpha, \theta) \equiv\left(\alpha_{0}, \theta\right)$. Eq. (4) thus provides:

$$
\begin{aligned}
\sigma_{N}=\sqrt{\frac{E G_{c r}}{D}}\left[g\left(\alpha_{0}, 0\right)\right. & +g_{1}\left(\alpha_{0}, 0\right) \frac{c_{f}}{D} \\
& \left.+\frac{1}{2 !} g_{2}\left(\alpha_{0}, 0\right)\left(\frac{c_{f}}{D}\right)^{2}+\ldots\right]^{-1 / 2}
\end{aligned}
$$

in which $g_{1}\left(\alpha_{0}, 0\right)=\partial g\left(\alpha_{0}, \theta\right) / \partial \theta . g_{2}\left(\alpha_{0}, 0\right)=g^{2} g\left(\alpha_{0}, \theta\right) \prime$ $\partial \theta^{2}, \ldots$, all evaluated at $\theta=0$. The last equation represents the large-size asymptotic series expansion of size effect. To obtain a simplified approximation. we now truncate the asymptotic series after the linear term. Then, with the notations:

$$
D_{0}=c_{f} \frac{g_{1}\left(\alpha_{0}, 0\right)}{g\left(\alpha_{0}, 0\right)}, \quad B f:=\sqrt{\frac{E G_{f}}{c_{f} g_{1}\left(\alpha_{0}, 0\right)}}
$$

the following size effect of fractal fracture is obtained:

$$
\sigma_{N}=B f_{i} D^{(d,-1) / 2}\left(1+\frac{D}{D_{0}}\right)^{-1 / 2}
$$

For the nonfractal case, $d_{f} \rightarrow 1$, this reduces to the size effect law deduced by Bazant (1983, 1984), which reads

$$
\sigma_{N}=\frac{B f_{i}^{\prime}}{\sqrt{1+\beta}}, \beta=\frac{D}{D_{0}}
$$

in which $\theta$ is called the brittleness number (Bazant 1987: BaZant and Pfeiffer, 1987).

For geometrically similar fracture test specimens, $\alpha_{0}$ is constant (independent of $D$ ), and so is $D_{0}$. For brittle failures of geometrically similar quasibrittle structures without notches, it is often observed that the crack lengths at maximum load are approximately geometrically similar. For concrete structures. the geometric similarity of cracks at maximum load has been experimentally demonstrated for diagonal shear of beams. punching of slabs, torsion. anchor pullout or bar pullout, and bar splice failure, and is also supported by finite element solutions (e.g., ACl, 1992; Bazant et al., 1994) and discrete element (random particle) simulations (Bažant et al., 1990), albeit for only a limited size range of $D$. Thus, $k, c_{0}, D_{0}, \sigma_{N}^{0}$ and $B f^{\prime}$ are all constant. In these typical cases, $(8)$ and (9) describe the dependence of $\sigma_{N}$ on size $D$ only, that is, the size effect. Figure 


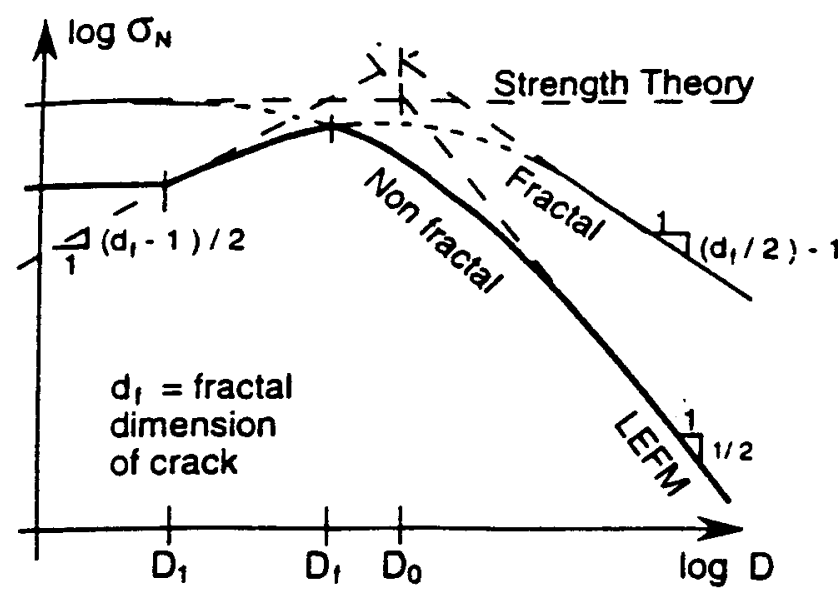

Fig. 2 Size effect curves obtained for geometrically similar specimens with nonfractal and fractal cracks and finite size of tracture process zone (possible transition to horizontal line for nonfractal behavior is shown for $D<D_{1}$ )

2 shows the size effect plot of $\log \sigma_{N}$ versus $\log D$ at constant $\alpha_{0}$. Two size effect curves are shown: (1) the fractal curve and (2) the nonfractal curve (for which the possibility of a cut-oif of fractality at the left end is considered in the plot).

The curve of fractal scaling obtained in Fig. 2 does not agree with the bulk of the aforementioned experimental evidence (for concrete, see e.g., Bažant et al., 1994). Just to give some example. Fig. 3 shows the data for size effect measured on double edge-notched and single edge-notched tensile fracture specimens of carbon fiber epoxy composites used in aerospace industry (Bažant et al., 1995), and Fig. 4 shows the data for size effect measured by Bazant and Pfeiffer (1987) on three types of fracture specimens of concrete and mortar. So it must be concluded that the size effect is not significantly affected nor explained by the fractal nature of crack surfaces in quasibrittle materials.

The aforementioned objection to the fractal hypothesis is not the only one. The fracture front in quasibrittle materials does not consist of a single crack. but a wide band of microcracks, which all must form and dissipate energy before the fracture can propagate. Only very few of the microcracks and slip planes eventually coalesce into a single continuous crack, which forms the final crack surface with fractal characteristics. Thus, even though the final crack surface may be to a large extent fractal,

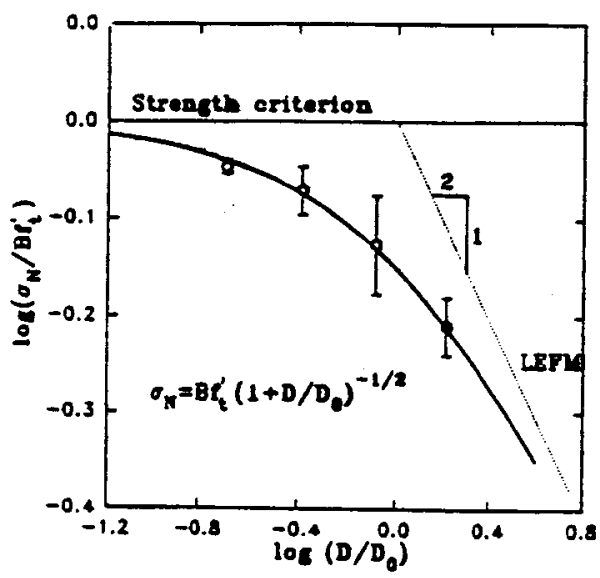

Fla 3 stev effect on nominel sungeth measured on croae-phy specimens of cabon-epoxy compoeite leminates with double-edes notches (the circtes show the average veluec, and the vertical segments show the maximum resch of random seatter). Arter Betiant, Deniw and $U$ (1996)
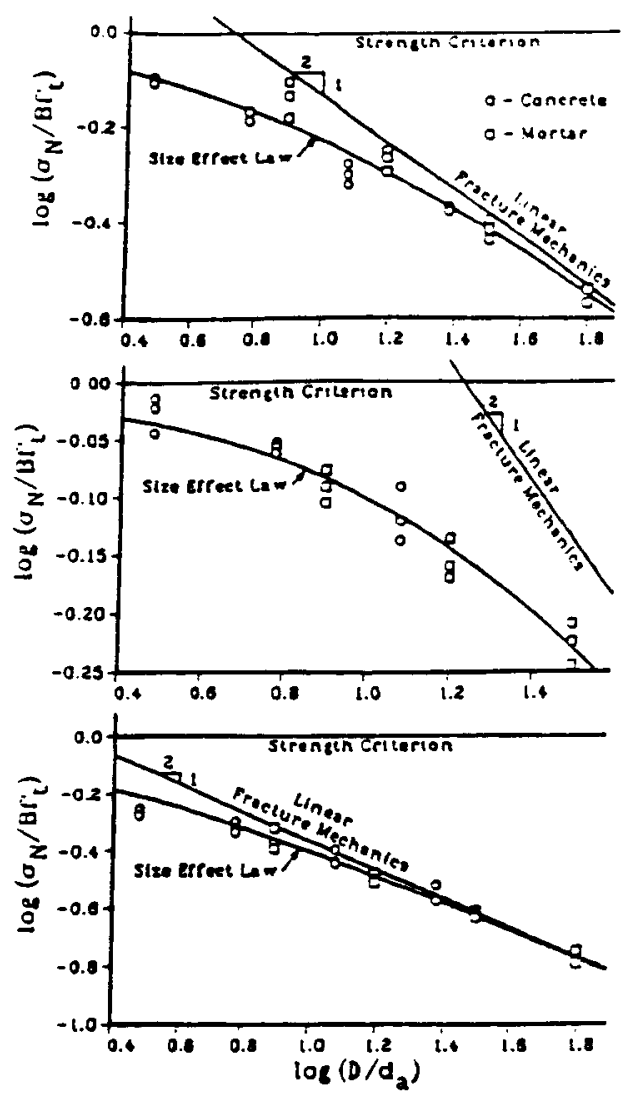

Fig. 4 Size effect on nomind strength mesesured on concrete and mortar specimens (top: throe-point bend specimens, middle: double edgenotched centric tension specimens, bottom: eccentric compression symmetrically edge-notched specimena: $d_{0}=$ maximum aggregate size). After Batant and Preiffer (1987).

the fractality cannot be relevant for the fracture process zone advance. Most of the energy is dissipated in the fracture process zone by microcracks (as well as plastic-frictional slips) that do not become part of the final crack surface and thus can have nothing to do with the fractality of the final crack surface.

So it appears one ought to distinguish two types of fractality: (1) Fractality of the final crack surface, which is an undisputed morphological feacure (although only for a limited range of scales); and (2) fractality of the fracture process controlling energy dissipation. The latter cannot be a significant property of quasibrittle materials.

There is another, conceptual, problem. Unlike the shoreline of England, the crack must have a morphology that is kinematically admissible. such that the zones of material adjacent to the crack face could move apart as two rigid bodies. But a fractal curve can have recessive segments and even spiraling segments which preclude such movement.

\section{Extensions and Ramifications of Asymptotic Anal- ysis}

Material length $c_{f}$ can, in particular, be rigorously and unambiguously defined as the LEFM-effective length (measured in the direction of propagation) of the fracture process zone in a specimen of infinite size. In that case, $\theta=c_{f} / D=\left(a-a_{n}\right) / D$ $=\alpha-\alpha_{0}$, and so $g(\alpha, \theta)$ reduces to the LEFM function of one variable, $g(\alpha)$. Also, $g\left(\alpha_{0}, 0\right)$ reduces to $g\left(\alpha_{0}\right), \partial / \partial \theta=$ $d / d \alpha$, and $g_{1}(\alpha, 0)$ takes the meaning of $g^{\prime}(\alpha)=d g(\alpha) / d \alpha$. Equation (7) thus yields: 


$$
\begin{gathered}
D_{0}=c_{f} \frac{g^{\prime}\left(\alpha_{0}\right)}{g\left(\alpha_{0}\right)}, \quad B f_{i}^{\prime}=\sqrt{\frac{E G_{f}}{c_{f} g^{\prime}\left(\alpha_{0}\right)}} . \\
\sigma_{N}^{0}=\sqrt{\frac{E G_{f} d_{f} \alpha_{0^{\prime}}^{d^{\prime}-1}}{c_{f} g^{\prime}\left(\alpha_{0}\right)}}
\end{gathered}
$$

and so Eq. (8) takes the form:

$$
\sigma_{N}=\sqrt{\frac{E G_{f l} d_{f} \alpha_{0^{\prime}}-1}{g^{\prime}\left(\alpha_{0}\right) c_{f}+g\left(\alpha_{0}\right) D}}
$$

The advantage of this equation is that its parameters are directly the material fracture parameters. For $d_{f}=1$, Eq. (11) reduces to the form of size effect law derived in a different manner by Bažant and Kazemi (1990, 1991) (also Eq. 12.2.11 in Bažant and Cedolin, 1991). Fitting this equation to size effect data, which can be done easily by rearranging the equation to a linear regression plot. one can determine $G_{f}$ or $G_{f l}$ and $c_{f}$. This serves the basis of the size effect method for measuring the material fracture parameters, which has been adopted by RIIEM as an international standard for concrete.

Alternatively, one may introduce more general dimensionless variables $\xi=\theta^{\prime}=(c, D)^{r}, h\left(\alpha_{0}, \xi\right)=\left[g\left(\alpha_{0}, \theta\right)\right]^{r}$, with any $r>0$. Then, expanding in Taylor series function $h\left(\alpha_{0}, \xi\right)$ with respect to $\xi$, one obtains by a similar procedure as before a more general large-size asymptotic series expansion (whose nonfractal special case was derived in Bazant, 1985, 1987):

$$
\sigma_{N}=\sigma_{P}\left[\beta^{r}+1+\kappa_{1} \beta^{-r}+\kappa_{2} \beta^{-2 r}+\kappa_{3} \beta^{-3 r}+\ldots\right]^{-1 / 2 r}
$$

where $\beta=D / D_{0}$ and $\kappa_{1}, \kappa_{2}, \ldots$ are certain constants. However, based on experiments as well some limit properties, it seems that $r=1$ is the appropriate value for most cases.

It may be noted that, by retaining more terms of the largesize asymptotic expansion (12), the accuracy can be improved. but only for large $D$. The expansion in Eq. (12) diverges for $D \rightarrow 0$. To get a better description of the size effect for small $D$, one needs a small-size asymptotic expansion.

The previous energy release rate equation $\left(\sigma_{N}^{2} / E\right) D g(\alpha, \vartheta)$ $=\epsilon_{\mathrm{cr}}(\mathrm{Eq} .4)$ is not meaningful for constitutive models such as the smeared cracking or the continuum damage mechanics. For such models, the material failure must be characterized by $N$, rather than $G_{f}$. Therefore, instead of Eq. (4), the energy balance equation (first law) for $\partial \sigma_{N} / \partial a=0$ (second law) must now be written in the form $\sigma_{N}^{2}[\psi(\alpha, \eta)]^{\prime} / E=W$, where $\psi(\alpha, \eta)=$ dimensionless function of dimensionless variables $\alpha=a / D$ and $\eta=\left(D / c_{f}\right)^{r}=\vartheta^{-r}$ (vanable $\vartheta$ is now unsuitable because $\vartheta \rightarrow$ $x$ for $D \rightarrow 0$ ), and exponent $r>0$ is introduced for the sake of generality. same as before. Because, for very small $D$, there is a diffuse failure zone, a must now be interpreted as the characteristic size of the failure zone, e.g., the length of cracking band. The same procedure as before now furnishes:

$$
\sigma_{N}=\sigma_{P}\left[1+\beta^{r}+b_{2} \beta^{2 r}+b_{3} \beta^{3 r}+\ldots\right]^{-1 / 2 r}
$$

in which $b_{2}, b_{3}, \ldots$ are certain constants and

$$
\begin{gathered}
\sigma_{p}=\sqrt{\frac{E G_{f \prime}}{c_{f}^{2-\alpha_{f}\left[\psi\left(\alpha_{0}, 0\right)\right]^{\prime}}}} \\
D_{0}=c_{f}\left[\frac{1}{\psi\left(\alpha_{0}, 0\right)} \frac{\partial \psi\left(\alpha_{0}, 0\right)}{\partial \eta}\right]^{-1 / r}
\end{gathered}
$$

Equation (14) represents the small-size asymptotic series expansion. This expansion of course cannot correctly describe the asymptotic limit for $D \rightarrow \infty$.

One important common feature of the large-size and smallsize asymptotic series expansions in Eqs. (12) and (14) is that they have in common the first two terms. Thus, if either series is truncated after the second term, it reduces to the same generalized size effect law (Bazant, 1985):

$$
\sigma_{v}=\sigma_{p}\left(1+\beta^{r}\right)^{-1 / 2 r} \quad\left(\beta=D / D_{0}\right)
$$

Since this law, including its special case for $r=1$, is anchored to the asymptotic cases on both sides and shares with both expansions the first two terms, it may be regarded as a matched asymptotic, that is, an intermediate approximation of uniform applicability for any size of the structure (e.g., Bender and Orszag, 1978: Barenblatt, 1979). Based on experience, the value $r=1$ appears, for various reasons, most appropriate for practical use.

In some types of failure, such as compression failures and especially the brazilian split-cylinder test, a plastic mechanism can operate simultaneously with fracture. In that case, the following generalization with nonzero residual nominal strength $\sigma$, may be used (Bažant. 1987):

$$
\sigma_{N}=\sigma_{P}\left(1+\beta^{r}\right)^{-1 / 2 r}+\sigma_{r}
$$

Unnotched quasibrittle structures that reach the maximum load when the crack initiates from a smooth surface, as exemplified by the bending test of modulus of rupture $f_{r}$ of a plain concrete beam, require a different approach. Applying the size effect law in Eq. (8) or (9) for the case $\alpha_{0} \rightarrow 0$ is impossible because $g\left(\alpha_{0}, 0\right)$ vanishes as $\alpha_{0} \rightarrow 0$. To deal with this case. one must truncate the large-size asymptotic series expansion only after the third term. Then, considering that $r=1$ and $g\left(\alpha_{0}\right.$, $0)=0$, and restricting attention to the nonfractal case, the same derivation as that which led to Eq. (11) fumishes

$$
\sigma_{s}=\sqrt{\frac{E G_{f}}{g^{\prime}(0) \varepsilon_{f}+\frac{1}{2} g^{\prime \prime}(0) c_{f}^{2} D^{-1}}}=\sigma_{N}^{=}\left(1-\frac{2 D_{b}}{D}\right)^{-1 / 2}
$$

in which $\sigma_{N}^{*}=\sqrt{E G_{f} / g^{\prime}(0) c_{f}}$ and $D_{b}=-\left[g^{\prime \prime}(0) / 4 g^{\prime}(0)\right] c_{f}$, with subscript $b$ referring to the boundary layer, in which the crack tip is located during crack initiation; and $\bar{c}_{f}=k c_{f}$ where $\kappa=$ constant $\geq 1$ but close to 1 . The reason that $\bar{c}_{f} \geq c_{f}$ is that the fracture process zone for fracture initiation without a notch may be expected to be larger than for a crack starting from a notch. It is now convenieut to introduce the approximation (1 $-2 \xi)^{-1 / 2}=1+\xi$ with $\xi=D_{b} / D$. which is admissible because it does not change the size effect for large $D$. The resulting size effect law for failures at crack initiaiion from a smooth surface is

$$
\sigma_{N}=B f:\left(1+\frac{D_{b}}{D}\right)=f:\left[1-0.0634 g^{\prime \prime}(0) \frac{c_{f}}{D}\right]
$$

The first part of this equation was derived by Bazant et al. (1995) in a different manner: $f *$ is the modulus of rupture for infinitely large beam (but not so large that Weibull statistical size effect would become significant), and $B$ is a dimensionless parameter. It is important to note that the limiting value $g^{\prime}(0)$ is shape independent, and so is $B f_{r}^{*}$, provided that the crack does not initiate from a sharp comer tip; always $g^{\prime}(0)=1.12^{2} \pi$ which leads to the last expression in $(20)$. This equation can be arranged as a linear regression of $\sigma_{N}$ versus $1 / D$, which is again helpful for easy identification of the constants from tests.

By matching of the three asymptotic expansions, namely: (1) the large-size expansion for large $\alpha_{0}$, (2) the large-size expansion for vanishing $\alpha_{0}$, and (3) the small-size expansion for large $\alpha_{0}$, the following approximated universal size effect law valid for failures at both large cracks and crack initiation from a smooth surface may be derived:

$$
\begin{aligned}
\sigma_{N}=\sigma_{0}(1+ & \left.\frac{D}{D_{0}}\right)^{-1 / 2} \\
& \times\left\{1+\frac{1}{s}\left[\left(\eta+\frac{D}{D_{b}}\right)\left(1+\frac{D}{D_{0}}\right)\right]^{-1}\right\}^{\prime}
\end{aligned}
$$


where. denoting $g=g\left(\alpha_{0}\right), g^{\prime}=g^{\prime}\left(\alpha_{0}\right), g_{0}^{\prime}=g^{\prime}(0), g^{\prime \prime}=$ $g^{\prime \prime}\left(\alpha_{0}\right)$.

$$
\sigma_{0}=c_{v} \sqrt{\frac{E G_{f}}{c_{f} g^{\prime}}}, D_{0}=\frac{g^{\prime}}{g} c_{f}, D_{b}=\frac{\nu\left(g^{\prime \prime}\right)}{4 g^{\prime}} \overline{c_{f}}, \overline{c_{f}}=\kappa c_{f}
$$

$v\left(g^{\prime \prime}\right)=\left\langle-g^{\prime \prime}\right\rangle=$ negative part of $g^{\prime \prime} ; \eta=$ empirical constant close to $\mathrm{I} ; \kappa=\mathrm{I}$ for $\alpha_{0} \geq c_{f} . \kappa=$ constant $>\mathrm{I}$ for $\alpha_{0}=0(\kappa$ $\approx 1.4$ ).

Equation (19) can be proven by expressing $\sigma_{v}^{-2}$ in terms of $\vartheta$ and expanding it into Taylor series in $\vartheta$ about point $\vartheta=0$. This yields (11) if $\alpha_{0}>0$, and $\sigma_{v} / f:=1+D_{b} /\left(D+\eta D_{b}\right)$ if $\alpha_{0}=0$. The latter differs from (18) by constant $\eta$, but this does not affect the first two terms of the expansion in $D^{-1}$ in the denominator in Eq. (17). Introducing constant $\eta$ achieves that $\sigma_{V}$ be finite for $D \rightarrow 0$, for both $\alpha_{0}>0$ and $\alpha_{0}=0$. The reason for introducing the negative part of $g^{n}$ is that for $g_{0}^{n}>$ 0 the crack cannot initiate at the surface (because the stresses before fracture are not maximum at the surface).

\section{Review of Some Recent Applications}

5.1 Size Effect Tests of Fracture Characteristics of Car. bon-Epoxy Laminates. Measurements of the size effect on the nominal strength of notched geometrically similar specimens of fiber composite laminates were conducted by Bažant et al. (1995). Tests were made on graphite/epoxy laminates made of $0.127 \mathrm{~mm}$ thick unidirectional plies. The specimens were rectangular strips of 0.25. 0.5.1. and 2 in. widths and 1 , 2,4 , and $8 \mathrm{in}$. lengths. One set of specimens had double-edge notches and a $\left[0 / 90_{2}\right]$, cross-ply layup, and another set of specimens had a single-sided edge notch and a [0/ $\pm 45 / 90]$, quasiisotropic layup.

A significant size effect was observed in these tests. It was found to approximately agree with Eq. (9) and (11); see Fig. 3. Optimum fits of the test results with the size effect formula in Eq. (11) were obtained, and the size effect law parameters determined by linear regression were then used to identify the material fracture characteristics, particularly the fracture energy $G_{f}$ and the effective length $c_{f}$ of the fracture process zone. Because the crossply laminate is not isotropic but orthotropic, the LEFM energy release rate function $g(\alpha)$ was determined according to the recent solution of the stress intensity factor for orthotropic specimens of the geometry used, which had been obtained by Bao et al. (1992). Comparisons of the test results to the size effect law for the cross-ply and quasi-isotropic laminates are shown in Fig. 3, in which the circles represent the nominal strengths measured in individual tests.

The R-curves were determined on the basis of the maximum load data (Fig. 3), using the procedure proposed in Bazant and Kazemi (1990).

The results show that in design simations with notches or large traction-free cracks the size effect on the nominal strength of fiber composite laminates must be taken into account and can be described by the size effect theory expounded here.

5.2 Size Efrect in Particulate Material Model. Fracture of quasibrittle materials exhibiting a large zone of distributed cracking can be effectively simulated by the particle model. representing an adaptation of the discrete element method. It has been demonstrated that the size effect exhibited by particle models agrees quite well with the size effect law in Eqs. (9) or (11) (Bazant et al., 1990). This model was extended and refined in a recent study by Jirasek and Bazant (1995) and was applied to the determination of macroscopic fracture characteristics of the particulate material model. The particle locations have been generated randomly according to prescribed particle size distribution. The mechanical properties on the macroscale were characterized by a triangular elastic-softening force-displacement diagram for the interparticle links. An efficient aigo- rithm, based on replacing the stiffness matrix changes by inelastic forces applied as external loads, was developed. This algorithm made it possible to calculate the exact displacement increments in each loading without iterations and using only the elastic stiffness matrix. The size effect was simulated for geometrically similar notched three-point bend beams of sizes in the ratio $1: 2: 4: 8$. (Fig. S, top left). The average maximum loads of these beams calculated from about ten random particle simulations for each beam size were found to agree quite well with the size effect law in Eq. (9).

Fitting Eq. (11) to these data (Fig. 5, top right), which can be done by linear regression after this equation is rearranged. the effective macroscopic fracture characteristics, including $G_{f}$ and $c_{f}$, were determined. This was repeated for many different characteristics of the interparticle force-displacement relation specified as the input. In this manner, it was determined (Fig. 5 bottom) how $G_{f}$ and $c_{f}$ approximately depend on the microductility $\gamma_{f}$ and on the coefficient of variation $\omega_{f}$ of the randomly simulated values of microstrength $f_{m}$ (peak of the assumed triangular interparticle force displacement diagram), which was assumed to have a lognormal distribution. ( $y_{f}$ was defined as the ratio of interparticle displacement when the interparticle force is reduced to zero to the displacement at peak force.)

Obviously. study of the size effect is effective for determining the influence of the microscopic material properties on its macroscopic tracture characteristics.

\section{Is Weibull-Type Size Effect Significant for Quasi-} brittle Failure?

Before closing, it is proper to explain at least briefly why strength randomness is not considered in the present analysis of size effect. Until about a decade ago. the size effect observed on the nominal strength of structures has been universally explained by randomness of strength and was thought to be properly calculated according to Weibull theory. Recently, however, it has been shown (Bazant and Xi, 1991) that this theory cannot apply when large stable fractures can grow in a stable manner prior to maximum load, as is typical of quasibrittle materials.

The main reason is the redistribution of stresses caused by stable fracture growth prior to maximum load and localization of damage into a fracture process zone. If the Weibull probability integral is applied to the redistributed stress field, which has high stress peaks near the crack tip, the dominant contribution to the integral comes from the fracture process zone. The imporant point is that the size of this zone is nearly independent of ${ }_{\text {s }}$ structure size $D$. The contribution from the rest of the structure is nearly vanishing, which corresponds to the fact that the fracture cannot occur outside the process zone. Because, in specimens of different sizes, this zone has about the same size, the Weibull-type size effect must, therefore, disappear. In other words, the fracture is probabilistic, but only the random properties of the material in a zone of the same size decide the failure, even though the structures have different sizes.

A generalized version of Weibull-rype theory, in which the material failure probability depends not on the local stress but on the average strain of a characteristic volume of the material. has been shown to yield lead to the approximate size effect formula (Bažant and $\mathrm{Xi}, 1991$ ):

$$
\sigma_{N}=\frac{B f_{i}^{\prime}}{\sqrt{\beta^{2 n / m}+\beta}}
$$

in which $\boldsymbol{m}=$ Weibull modulus (exponent of Weibull distribution of random strength), which is typically about 12 for concrete, and $n=1,2$ or 3 for one-, two- and three-dimensional similarity. Typically, for $n=2$ or $3,2 n / m \& 1$, for concrete. Then, for $m \rightarrow \infty$, which is deterministic limit, this formula approaches the size effect law in (9). Also, for $D \rightarrow 0$, this formula asymptotically approaches the classical Weibull size 

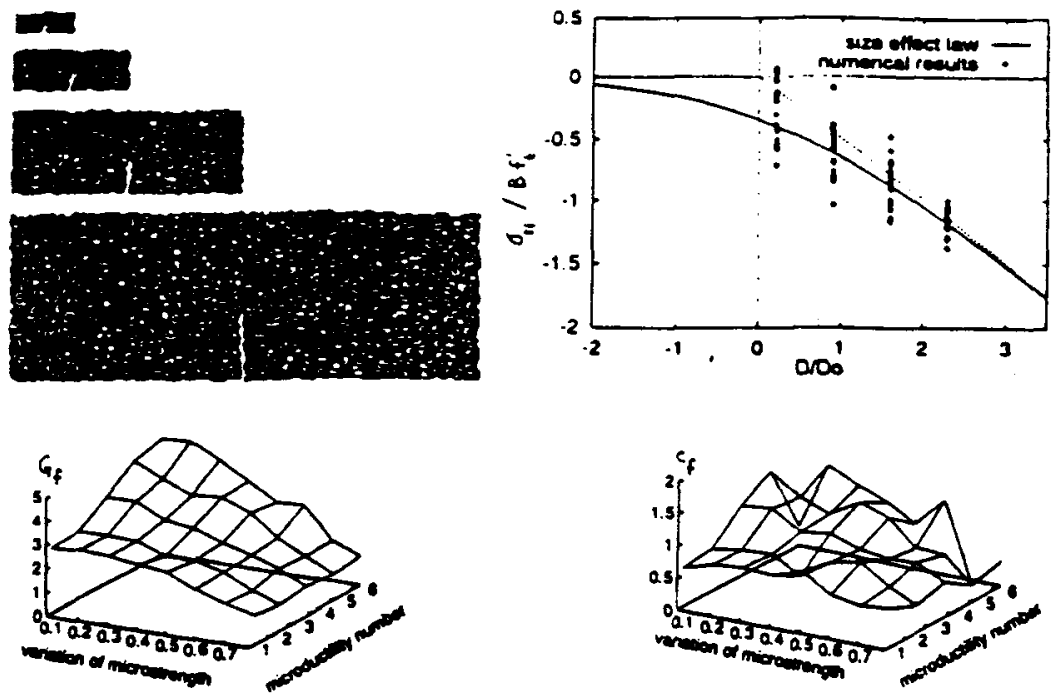

Fig. 5 Size effect simulations using a random particle model ltop left examples of randomly generated truseses representing three-point bend fracture specimens represented as particle systems; top right: calculated nominal strengths for various sizes $D$ and their optimum fir with the dize effect law; bottom: surfaces of $G$, (loft) and $C$, (right) as functions of microductilly and the coefficient of variation of interparticle micro-strength). After Jirtsok and Betant (1995).

effect law, and for large sizes and any $m$, this formula asymptotically approaches Eq. (9). It has been shown that the difference between these two formulas for concrete structures is significant only for extremely small sizes, which are below the applicability of continuum modeling.

Thus, for quasibriale materials, the Weibull-type size effect might be taking place only in very large structures that fail right at crack initiation. Because, for beam depths such as $D=10 D_{b}$, the (deterministic) stress redistribution in the boundary layer, underlying Eq. (18). is still significant, the beam depth beyond which the Weibull-type size effect could begin to dominate must be at least $D=100 D_{b}$. Hardly any case satisfying this condition exists in concrete practice, and probably not for other materials. Besides, the objective of producing good quasibrittle materials. that is, toughening them, is to achieve that $c$, be as large as possible. But this prevents them from failing right at crack initiation.

\section{Relations to Other Fracture Characteristics}

Since the determination of $G_{f}$ and $c$, by linear regression of maximum load data based on Eq. ( 6 ) is particularly easy. it is convenient to use the size effect method for determining the fracture parameters of other nonlinear fracture models as well. For example, the fracture toughness and the critical crack-tip opening displacement of Jenq-Shah two-parameter model for concrete fracture (which represents an adaptation of Wells' (1961) model for fracture of metals) may be calculated as

$$
\begin{aligned}
K_{k e}^{S} & =\sqrt{g\left(\alpha_{0}\right) D_{0} B} f_{i}^{\prime}=\sqrt{E^{\prime} G_{f}^{\prime}} \\
\delta_{C T O D}^{s} & =\frac{\sqrt{8}}{\pi E^{\prime}} \sqrt{g\left(\alpha_{0}\right)} g^{\prime}\left(\alpha_{0}\right) D_{0} B f_{\prime}^{\prime} \\
& =\frac{\sqrt{8}}{\pi} \frac{K_{k c}}{E^{\prime}} \sqrt{c_{f}}=\frac{\sqrt{8}}{\pi} \sqrt{\frac{G_{f}^{\prime} c_{f}}{E^{\prime}}}
\end{aligned}
$$

The R-curve can be obtained from

$$
\begin{gathered}
R(c)=G_{f} \frac{c g^{\prime}(\alpha)}{c_{f} g^{\prime}\left(\alpha_{0}\right)} \\
\frac{c}{c_{f}}=\frac{g^{\prime}\left(\alpha_{0}\right)}{g\left(\alpha_{0}\right)}\left(\frac{g(\alpha)}{g^{\prime}(\alpha)}-\alpha+\alpha_{0}\right)
\end{gathered}
$$

Choosing a series of values of $\alpha$. one can calculate from ( 25 the values of the crack extension from the tip of notch (or traction-free crack). $c=a-a_{0}$. For each of them. one can then evaluate $R(c)$ from (24) (Bazant and Kazemi. 1990). This $R$-curve. which represents the envelope of the curves of energy rate balance for similar specimens of different sizes, is of course strongly dependent on the geometry of the structure.

The cohesive crack model. pioneered for concrete by Hillerborg ( 1985$)$, is characterized by the softening curve $\sigma=\phi\left(u^{\circ}\right)$ relating the cohesive (crack-bridging) stress $\sigma$ to the opening displacement $w$. The main characteristics of this curve are the area $G_{f}^{C}$ under the complete curve $\phi(w)$ and the area $G_{f}^{l}$ under the initial tangent of this curve. It has been established computationally and experimentally (Karihaloo and Nallathambi, 1991: Planas and Elices, 1989) that

$$
G_{f}^{\prime} \approx G_{f}, \quad G_{f}^{c} \approx 2 G_{f}
$$

Thus. the value of $G$, resulting from the size effect law determines the initial slope of the softening $\phi(w)$ curve.

\section{Main Conclusions}

The size effect in quasibrittle structures can be analyzed on the basis of asymptotic series expansions and asymptotic matching. This approach, well known from fluid mechanics. is very powerful because, while for normal sizes the problem at hand is extremely difficult, it becomes much simpler both for very large sizes (LEFM) and for very small sizes (plasticity). Asymptotic matching is an effective way to obtain a simplified descnption in the normal, intermediate range of sizes. The size effect at crack initiation from a smooth surface can also be described the basis of the asymptotic energy release analysis. and a universal size effect law comprising both types of size effect can be formulated. Knowledge of the size effect law is usetul for identifying material fracture characteristics from tests.

The fractal aspect of the morphology of crack surfaces observed in quasibrittle materials does not appear to play a significant role in fracture propagation and the size effect.

The statistical size effect as described by Weibull's theory of random strength cannot play a significant role in quasibrittle structures, except for very large structures failing at crack initiation - an undesirable behavior. 


\section{Acknowledgment}

Partial financial support under ONR grant NO00 14-91J-1109 to Northwestem University and additional support from the ACBM Center at Northwestern University are gratefully acknowledged.

\section{References}

ACI Commirtee 446. 1992. "Fracture Mechanics of Concrete: Concepts. Models and Determination of Material Properties," State-of-Art Report of Am. Concrete Institute (ACI) in Fracture Mechanics of Concrete Structures. Z. P. Bazant. ed. Elsevier, London. pp. $1-140$.

Bao. G. Ho. S., Suo, Z., and Fan. B.. 1992. "The Role of Material Orthouropy in Fracture Specimens for Composites." Int. J. Solid Strucrures. Vol. 29(9). pp. $1105-1116$.

Barenblatt. G. I., 1979. Similarity. Self-Similariny and Intermediate Asymptotics, Consultants Bureau. New York. N.Y.

Batant, Z. P.. 1983. "Fracture in Concrete and Reinforced Concrete." Mechanics of Geomaserials: Rocks. Concreses. Soils. Preprints. IUTAM Prager Symposium held at Northwestem University. Z. P. Bazant ed., Evanston. IL. pp. 281 317.

Bažant. Z. P.. 1984, "Size Effect in Blunt Fracture: Concrete, Rock, Metal," J. of Engng. Mechanics. ASCE. Vol. 110, pp. 518-535.

Bazant. Z. P., 1985. "Fracture Mechanics and Strain-Softening in Concrete." Preprints. U.S. Japan Seminar on Fuite Element Analysis of Reinforced Concrete Structures. Tokyo, Vol. 1, pp. 47-69.

Bazant. Z. P.. 1987. "Fracure Energy of Heterogeneous Marérial and Similitude." Preprints. SEM-RULEM Int. Conf. on Fracture of Concrete and Rock. (Houston. Texas, June 1987), S. P. Shah and S. E. Swarz, eds.. publ. by SEM (Soc. for Expet. Mech.), pp. 390-402.

Bazant. Z. P., 1993. "Scaling Laws in Mechanics of Failure." J. of Engrg. Mech. ASCE. Vol. 119 (9), pp. 1828-1844.

Bazant, Z. P., 1993. "Size Effect in Tensile and Compressive Quasibritule Failures." Preprints, JCI International W'orkshop on Size Effect in Concrete Struc tures. Tohoku University. Sendai. Japan. Oct. 141-160; also Prnceedings. Size Effect in Concrese Strucrures. H. Mihashi, H. Okamura and Z. P. Batant, eds. E. \& F. N. Spon. London-New York, 1994, pp. 161-180.

Bażant. Z P.. and Cedolin, L. 1991. Stability of Sinuctures: Elastic. Inelastic. Fracture and Damage Theories (textbook and refereace volume). Oxford University Press, New York

Bazane Z. P.. Daniel, I., and Li. Z. 1995. "Size Effect and Fracture Characteristics of Fiber-Composite Laminates," Report. Depl. of Civil Engng., Northwestern University, Evanston, Illinois; also ASME JEMT, submitted to.

Bazane, Z. P., and Kazemi, M. T., 1991, "Size Effect on Diagonal Shear Failure of Beams Without Stimups." ACI Structural J., Vol. 88. pp. 268-276.

Bazant Z. P., and Kazemi. M. T.. 1990, "Size Effect in Fracture of Ceramics and its Use to Determine Fracture Energy and Effective Process Zone Length." J. of American Ceramic Soctery. Vol. 73 (7). pp. 1841-1853.

Bazanh, Z P., Li, Zhenghi, and Li. Yuan-Neg, 1995. "Modulus of Rupare: Size Effect Due to Fracture Initiation in Boundary Layer," J. of Srrucrural Engrg. ASCE Vol. 121, in prest.

Batanc Z. P.. Lin. F.-B., and Lippmann. H. 1993. "Frecture Energy Release and Size Effect in Borebole Breakoul," Int Soumal for Nunerical and Anatyrical Methods in Geomechanics, Vol. 17, pp. 1-14.

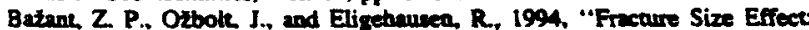
Review of Evidence for Concreve Structures." J. of Smuct Engrs. ASCE, Vol. 120 (8), pp. 2377-2398.

Batane, Z P., and Pfeiffer, P. A., 1987, "Detarminacion of Fracture Eneryy from Size Effect and Brialeness Number," ACI Materials Jour., Vol. 84, pp. $463-480$.

Bazant, Z P., Tabbark M. R. Karemi, M. T., and Pijudier-Cabot, G. 1990 "Random Particle Model for Frncture of A raregate or Fiber Composites." ASCE J. of Engng. Mech. VoL 116 (8) pp. 1686-170s.

Batome, Z. P., and Xi. Y., 1991, "Stutistical Size Effect in Quni-Brittle Structures: II. Nonlocal Tbeory." ASCE J. of Engineering Mecharics, Vol. 117 (11), p. 2623-2640.

Bender, M. C., and Orsans 5 A. 1978, Advanced Mathematical Methods for Scientists and Engineers, MoCow-Hill, New York, Chapters 9-11
Borodich $F, 1997$. Eracture Energy of Facial Cack. Propagacon in Cuocete

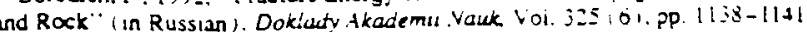
Carpunter. A. 1986. Mechanical Damage and Crack Growih in Concrete. Marinus Nijhoff Publishers. Doordrecht.

Cappinteri. A.. Chiaia, B., and Ferro, G., 1993. "Multifractal Scaling Law for the Nominal Strength Variation of Concrete Structures." Size Effect in Concrete Sirucrures, Proc., Japan Concrete Institute Intern. Workshop held in Sendas. Japan. Nov. 1995. M. Mihashi. H. Okamura and Z. P. Bazant. eds.. E. \& F. N. Spon. London-New York. pp. 193-206.

Carpinteri. A.. Chiaia. B., and Ferro. G., 1995. "Multiftactal Nature of Material Microstructure and Size Effects on Nominal Tensile Strength." Fracture of Brizle Disordered Materials: Concrete, Rock and Ceramics, Proc.. IUTAM Symp. Uoiv. of Qeensland. Brisbane. Sept. 1993), G. Baker and B. L. Karihaloo, eds.. E. \& F. N. Spon, London. pp. $21-50$.

Carpinceri. A. 1994. "Fractal Nature of Material Microscructure and Size Effects on Apparent Mechanical Properties." Mechanics of Marerials, Vol. 18, pp. 89-101.

Cahn. R. 1989, "Fractal Dimension and Fracture," Varure, Vol. 338. Mar.. pp. 201-202.

Gemu. R., Bazant, and Karr, M. E., 1990. "Fracture Properties and Brituleness of High-Strength Concrete." ACl Materials Joumal, Vol. 87, Nov,-Dec., pp. $608-618$.

Hillerborg. A 1985a "Theoretical Basis of Method to Determine the Fracture Energy $G_{f}$ of Concrete." Materiais and Sinuctures, Vol. 18 (106), pp. $291-996$.

Jirasek. M., and Bazant. 1995. "Macroscopic Fracnure Charactenstics of Random Particie Systems," Intem. J. of Fracture, Vol. 69 (3). pp. 201 -228.

Karihaloo. B. L. and Vallathambi. P. 1991, "Notched Beam Test: Mude Fracture Toughness." Fracture .Hechanics Test Methods for Concrete. by S. P. Shah and A. Carpinteri. eds., Chapman and Hall. London. pp. 1-86.

Lange D. A. Jennings, H. M., and Shah, S. P., 1993. "Relationship Berween Fracture Suriace Roughness and Fracture Behaviot of Cement Paste and Morta." J. of .tn Ceramic Soc. Vol. 76 (3). pp. 589-597.

Li. Y.-N.. and Bazzant. Z. P., 1994, "Eigenvalue Analysis of Size Effect for Cohesive Crack Model." Intemational J. of Fracture. Vol. 66. pp. 213-224.

Mart. P., 1989, "Size Effect in Double-Punch Tests on Concreie Cylinders." ACI Mareriais J., Vol. $86(6)$, pp. $597-601$

Mandelbroc. B. B.. Passoja. D E.. and Paullay, A.. 1984. "Fractal Charscter of Fracture Surfaces of Mecals," Narure, Vol. 308, pp. 72t-722.

Mecbolsky, J. J., and Mackin. T. J.. 1988. "Fractal Analysis of Fracture in Ocala Chert." J. Mat. Sci. Latters. Vol. - pp. 1145-1147.

Moiosov, A. B.. and Borodich. F. M.. 1992, "Fractal Fracture of Britte Boties Under Compression" (in Russian), Doklacty Akademii Nauk, Vol. 324 (3), pp. 546-549.

Planas. J., and Elices, M.. 1988a. "Size Effect in Concrete Structures: Mrhematical Approximations and Experimental Validation." Cracking and Damage. Strain Localization and Size Effect. Proc. of France-U.S. Workshop. Cactan. France. J. Mazars and Z. P. Bazanl eds. Pp. $462-476$.

Planas. J., and Elices. M.. 19886. "Concepual and Experimental Problems in the Decermination of the Fructure Energy of Concrete." Proc.. Ine Workshop on Fracture Toughness and Fracture Energy. Test Methods for Concrete and Rock, Toboku Univ., Sendai, Japan. pp. 203-212.

Planes. J., and Elices, M.. 1989. "Size Effect in Concrete Structures: Machemalical Approximations and Experimental Validation." in Crackins and Damese. by J. Mezars and Z P. Batant, eds., Elsevier, London, pp. 462-476.

Plans, J., and Elices, M., 1993, "Drying Shriniage Effect on the Modulus of Ruparre." Creep and Shrinkage in Concrete Structures. Proc.. ConCreep 5. Barcetone, Z P. Bazant and I. Carol, E. and F. N. Spon, eds., Loodon. Pp. 357368.

Sroume, V. C., Barton, C., and Gamatel-Din, N.. 1990, "Fractal Characterizaios of Concrete Cract Surfeces," Engrg. Frocture Mechanick, Vol. 35 (1).

Somme V. C. and Barton, C. C. 1994. "Fractals, Fractere and Size Effect in Concrete." I. of Engrg. Mechanics ASCE, Vol. 120 (4), pp. 835-854.

Sedor, L. I. 1959, Similarisy and Dimensional Methods in Mecranics. 1 co demic Press, New Yort.

Walsh. P. F., 1972. "Fracture of Plain Concrete" Indian Concr. J., Vol t6. No. 11.

Walsh, P. F., 1976. "Crack Initiation in Plain Concrete, Mag. of Concr. Res. Vol. 28, pp. $37-41$.

Welle A. A., 1961. "Unstable Crack Propagation in Metais-Cleavage and Fass Fracture," Symp. on Crack Propagarion. Cranfield. Vol. 1, pp. 210-230.

Xie. Heping, 1993. Fractals in Rock Mechanics. Balkema. Rotterdam. 164 pp. 